\title{
Pengaruh Kecerdasan Emosional, Komitmen Organisasional dan Organizational Citizenship Behavior terhadap Kinerja
}

\section{Permata Sakti*, Rossanto Dwi Handoyo, Ake Wihadanto}

Program Studi Magister Manajemen, Universitas Terbuka

Jl. Pondok Cabe Raya, Pd. Cabe Udik, Kec. Ciputat, Kota Tangerang Selatan, Banten, Indonesia

*Email: permatasakti@bps.go.id

\begin{tabular}{|c|c|}
\hline Artikel Info & ABSTRAK \\
\hline Dikirim: & $\begin{array}{l}\text { Badan Pusat Statisik (BPS) mempunyai visi sebagai penyedia data berkualitas yang dibutuhkan dalam } \\
\text { proses perencanaan, pemantauan dan evaluasi pembangunan bagi pemerintah maupun masyarakat. Fokus }\end{array}$ \\
\hline 2 Februari 2020 & $\begin{array}{l}\text { proses perencanaan, pemantauan dan evaluasi pembangunan bag1 pemerintah maupun masyarakat. Hoku } \\
\text { BPS saat ini adalah peningkatan kualitas data dan pelayanan prima sehingga peran pegawai BPS }\end{array}$ \\
\hline Revisi: & nususnya Koordinator Statistik Kecamatan (KSK) dalam meningkatkan kualitas data sangat pentin \\
\hline 28 Maret 2020 & Penelitian ini bertujuan untuk menganalisis pengaruh kecerdasan emosional, komitmen organisasion \\
\hline Diterima: & dan Organizational Citizenship Behavior terhadap kinerja KSK di BPS Kabupaten/Kota di Jawa Timu \\
\hline 20 April 2020 & sebanyak 447 orang dengan menggunakan software SmartPLS. Hasil penelitian menunjukkan bahy \\
\hline & komitmen organisasional berpengaruh positif tapi tidak mempunyai pengaruh yang signifikan terhade \\
\hline & kinerja KSK, sedangkan OCB dan kecerdasan emosional secara parsial masing-masing berpengaruh \\
\hline & $\begin{array}{l}\text { positif dan signifikan terhadap kinerja KSK. Variabel kecerdasan emosional, komitmen organisasional } \\
\text { dan OCB berpengaruh terhadap kinerja KSK sebesar } 75,89 \text { persen dan sebesar } 24,11 \text { persen dipengaruhi }\end{array}$ \\
\hline
\end{tabular}

Kata Kunci : Kecerdasan Emosional, Komitmen Organisasional, OCB, Kinerja, KSK, BPS

\section{Effects of Experiential Marketing, Self-efficacy and Trust on Repurchase Intention}

\begin{abstract}
Badan Pusat Statistik has a vision as a provider of quality data needed in the planning, monitoring, and evaluating development for the government and the community. The current focus of BPS is on improving data quality and excellent service so that the role of BPS staff, especially the District Statistics Coordinator (KSK) in improving data quality, is very important. This study aims to analyze the effect of emotional intelligence, organizational commitment, and Organizational Citizenship Behavior on the performance of KSK in Statistics of Regency / Municipality in East Java as many as 447 people using SmartPLS software. The results showed that organizational commitment had a positive effect but did not have a significant impact on the performance of KSK. In contrast, OCB and emotional intelligence partially had a positive and significant effect on KSK performance. Other factors influence variable emotional intelligence, organizational commitment, and OCB influence the performance of KSK by 75.89 percent and by 24.11 percent.
\end{abstract}

Keyword: Emotional Intelligence, Organizational Commitment, OCB, Performance, KSK, BPS

Cara Sitasi :

Sakti, P., Handoyo, R. D., \& Wihadanto, A.,(2020). Pengaruh Kecerdasan Emosional, Komitmen Organisasional dan Organizational Citizenship Behavior terhadap Kinerja. Jurnal Ilmiah Manajemen dan Bisnis, 21(1), 60-68. https://doi.org/10.30596/jimb.v21i1.4149 . 


\section{Jurnal Ilmiah Manajemen dan Bisnis}

ISSN 1693-7619 (Print) I ISSN 2580-4170 (Online) | http://jurnal.umsu.ac.id/index.php/mbisnis

\section{PENDAHULUAN}

Badan Pusat Statistik (BPS) adalah Lembaga Pemerintah Non Kementerian yang bertanggung jawab langsung kepada Presiden berdasarkan UU Nomor 16 Tahun 1997. BPS mempunyai visi sebagai penyedia data berkualitas yang dibutuhkan dalam proses perencanaan, pemantauan dan evaluasi pembangunan bagi pemerintah maupun masyarakat.

KSK merupakan pegawai fungsional pengumpul data statistik di kecamatan yang mengkoordinasikan kegiatan perstatistikan, mulai dari sosialisasi kegiatan, koordinasi dengan pemerintahan setempat, rekrutmen petugas, sampai dengan pelaksanaan lapangan. Koordinator Statistik Kecamatan harus berkoordinasi dengan Camat serta Kepala Desa/Lurah/Ketua RW/RT sebelum menyelenggarakan kegiatan perstatistikan.

Sebagai ujung tombak BPS, KSK harus mampu memenuhi tuntutan para pengguna data. Data yang berkualitas, cepat dan akurat sangat dibutuhkan oleh pengguna data sehingga peran BPS semakin dipertaruhkan. Dengan demikian tugas KSK semakin berat dan profesionalitas dalam bertugas juga semakin dituntut.

Tuntutan masyarakat terhadap kinerja BPS sebagai penyedia data statistik yang beragam dan berkualitas semakin hari semakin meningkat. masyarakat menginginkan ketersediaan data dengan lebih cepat (faster), lebih murah (cheaper), lebih mudah diperoleh (easier), dan lebih berkualitas (better). Gerakan satu data yang dicanangkan presiden mengakibatkan pekerjaan KSK semakin menumpuk dan tumpang tindih antara satu survei dengan survei lainnya.

Dalam kondisi seperti ini, KSK dihadapkan dengan dua tuntutan, yaitu bekerja tepat waktu dan hasil kerja yang berkualitas. Pekerjaan yang menumpuk bukan alasan kualitas data jelek, sehingga diperlukan strategi dalam bekerja. KSK merupakan salah satu faktor penentu kualitas data BPS. Berasal dari KSK inilah produk utama BPS dihasilkan. Karena itulah pembekalan pengetahuan sangat diperlukan KSK. Selain melakukan pendataan, KSK juga sebagai humas atau agen sosialisasi kegiatan BPS. KSK berperan sebagai humas merupakan salah satu cara sosialisasi yang efektif dalam mengedukasi masyarakat akan pentingnya data. Data yang berkualitas hanya dapat diwujudkan dengan komitmen KSK untuk profesional, amanah dan berintegritas dalam bekerja yang diawali dari diri sendiri. Komitmen organisasi sangat berpengaruh penting terhadap pencapaian hasil yang maksimal.

Namun kenyataan yang terjadi di lapangan, kinerja KSK sebagai ujung tombak BPS belum tercapai maksimal. Kualitas dan keakuratan data BPS masih banyak dipertanyakan oleh berbagai pihak, begitu pula dengan ketepatan waktu penyelesaian survey dan pemasukan dokumen. Terlihat dari segi kualitas dokumen yang dihasilkan oleh KSK. Sering ditemukan ketidak konsistenan antara jawaban dengan pertanyaan survey sehingga pengawas harus lebih teliti lagi dalam memeriksa dokumen dan kadangkala dokumen yang sudah masuk dikembalikan kepada KSK untuk diperbaiki isian dan konsistensinya.

Goleman (2015) berpendapat bahwa kecerdasan emosi menyumbang $80 \%$ dari faktor penentu kesuksesan seseorang dan $20 \%$ lainnya ditentukan oleh kecerdasan intelektual. Sementara Luthans (2006) mengatakan bahwa komitmen organisasi merupakan sikap yang merefleksikan loyalitas karyawan pada organisasi dan proses berkelanjutan di mana anggota organisasi mengekspresikan perhatiannya terhadap organisasi dan keberhasilan serta kemajuan 


\section{Jurnal Ilmiah Manajemen dan Bisnis}

ISSN 1693-7619 (Print) I ISSN 2580-4170 (Online) | http://jurnal.umsu.ac.id/index.php/mbisnis

yang berkelanjutan. OCB (Organizational Citizenship Behavior) merupakan perilaku individual yang bersifat sukarela yang tidak secara langsung diakui oleh organisasi dan apabila OCB dilakukan bersama-sama akan bisa meningkatkan fungsi organisasi tersebut secara efektif (Organ, 2006). Variabel kecerdasan emosional, komitmen organisasional dan Organizational Citizenship Behavior dapat mempengaruhi kinerja KSK, akan tetapi tidak semua variabel tersebut telah dimiliki oleh KSK.

Berdasarkan uraian diatas maka yang menjadi pokok permasalahan dalam penelitian ini adalah apakah kecerdasan emosional, komitmen organisasional dan Organizational Citizenship Behavior sama-sama berpengaruh positif terhadap kinerja KSK di Provinsi Jawa Timur? Kemudian tujuan yang ingin dicapai dari penelitian ini adalah untuk menganalisis pengaruh kecerdasan emosional, komitmen organisasional, Organizational Citizenship Behavior terhadap kinerja KSK di Provinsi Jawa Timur.

\section{METODE}

Penelitian ini menggunakan metode deskriptif kuantitatif. Sedangkan sifat penelitian ini bersifat deskriptif explanatory yaitu bertujuan mengurai dan menjelaskan kedudukan variabel yang diteliti serta hubungannya dengan variabel yang lain. Populasi sampel yang diteliti adalah Koordinator Statistik Kecamatan yang berstatus PNS/ASN dan bertugas di lingkungan BPS Kabupaten/Kota se-Jawa Timur, dimana sampai dengan 1 Januari 2019 Koordinator Statistik Kecamatan berjumlah 447 orang. Kemudian menggunakan Rumus Slovin didapatkan jumlah sampel minimal sebanyak 211 orang.

Pengumpulan data dilakukan melalui kuesioner yang disusun menggunakan skala Likert. Pengukuran variabel bebas dan variabel terikat dalam kuesioner memakai skala Likert lima poin yaitu mulai dari Sangat Setuju ( $\mathrm{SS}=5$ ); Setuju ( $\mathrm{S}=4$ ); Kurang Setuju $(\mathrm{KS}=3)$; Tidak Setuju (TS=2) dan Sangat Tidak Setuju (STS=1). Pengolahan data dilakukan dengan metode Partial Least Square (PLS). PLS adalah metode penyelesaian Structural Equation Modelling (SEM) yang dalam hal ini lebih tepat dibandingkan dengan teknik-teknik SEM lainnya karena jumlah sampel kecil dan potensi distribusi variabel yang tidak normal. Pengolahan data dilakukan dengan software SmartPLS 2.0 untuk menguji hubungan antar variabel.

\section{HASIL DAN PEMBAHASAN}

Deskriptif profil responden menunjukkan bahwa profil KSK yang bertugas di Jawa Timur mempunyai karakteristik mayoritas sebagai berikut : berusia antara 41-50 tahun (34,6\%), berjenis kelamin laki-laki $(86,26 \%)$, berlatarbelakang pendidikan S1 - S2 $(49,76 \%)$ dan masa kerja $11-20$ tahun $(47,87 \%)$.

Tabel 1. Jawaban Responden Berdasarkan Kelompok Umur

\begin{tabular}{|c|c|c|c|c|c|c|c|}
\hline \multirow[b]{2}{*}{ No. } & \multirow[b]{2}{*}{$\begin{array}{l}\text { Kategori } \\
\text { Umur }\end{array}$} & \multirow[b]{2}{*}{ Persentase } & \multicolumn{4}{|c|}{ Rata-rata (Mean) } & \multirow[b]{2}{*}{$\begin{array}{c}\text { Rata-rata } \\
\text { Keseluruhan }\end{array}$} \\
\hline & & & $\begin{array}{l}\text { Kecerdasan } \\
\text { Emosional }\end{array}$ & $\begin{array}{c}\text { Komitmen } \\
\text { Organisasional }\end{array}$ & OCB & $\begin{array}{l}\text { Kinerja } \\
\text { KSK }\end{array}$ & \\
\hline 1. & $<31$ Thn & 9,95 & 3,99 & 3,63 & 4,09 & 4,03 & 3,94 \\
\hline 2. & 31-40 Thn & 30,33 & 4,05 & 3,86 & 4,16 & 3,99 & 4,02 \\
\hline 3. & 41-50 Thn & 34,60 & 4,18 & 4,06 & 4,24 & 4,08 & 4,14 \\
\hline 4. & > 50 Thn & 25,12 & 3,97 & 3,90 & 3,94 & 3,88 & 3,92 \\
\hline
\end{tabular}




\section{Jurnal Ilmiah Manajemen dan Bisnis}

ISSN 1693-7619 (Print) I ISSN 2580-4170 (Online) | http://jurnal.umsu.ac.id/index.php/mbisnis

Tabel 2. Jawaban Responden Berdasarkan Jenis Kelamin

\begin{tabular}{lccccccc}
\hline No. & $\begin{array}{c}\text { Jenis } \\
\text { Kelamin }\end{array}$ & Persentase & $\begin{array}{c}\text { Kecerdasan } \\
\text { Emosional }\end{array}$ & $\begin{array}{c}\text { Rata-rata (Mean) } \\
\text { Komitmen } \\
\text { Organisasional }\end{array}$ & OCB & $\begin{array}{c}\text { Kinerja } \\
\text { KSK }\end{array}$ & $\begin{array}{c}\text { Rata-rata } \\
\text { Keseluruhan }\end{array}$ \\
\hline 1. & Laki-laki & 86,26 & 4,10 & 4,00 & 4,14 & 4,01 & 4,06 \\
2. & Perempuan & 13,74 & 3,89 & 3,36 & 4,01 & 3,91 & 3,79 \\
\hline
\end{tabular}

Tabel 3. Jawaban Responden Berdasarkan Pendidikan

\begin{tabular}{|c|c|c|c|c|c|c|c|}
\hline \multirow[b]{2}{*}{ No. } & \multirow[b]{2}{*}{ Pendidikan } & \multirow[b]{2}{*}{ Persentase } & \multicolumn{4}{|c|}{ Rata-rata (Mean) } & \multirow[b]{2}{*}{$\begin{array}{l}\text { Rata-rata } \\
\text { Keseluruhan }\end{array}$} \\
\hline & & & $\begin{array}{l}\text { Kecerdasan } \\
\text { Emosional }\end{array}$ & $\begin{array}{l}\text { Komitmen } \\
\text { Organisasion } \\
\text { al }\end{array}$ & OCB & $\begin{array}{c}\text { Kinerja } \\
\text { KSK }\end{array}$ & \\
\hline 1. & $\begin{array}{l}\text { SMA } \\
\text { Sederajat }\end{array}$ & 33,65 & 4,03 & 4,09 & 4,09 & 3,97 & 4,04 \\
\hline 2. & D1 - D3 & 16,59 & 4,01 & 3,73 & 4,10 & 4,00 & 3,96 \\
\hline 3. & $\mathrm{~S} 1-\mathrm{S} 2$ & 49,76 & 4,12 & 3,86 & 4,16 & 4,02 & 4,04 \\
\hline
\end{tabular}

Tabel 4. Jawaban Responden Berdasarkan Masa Kerja

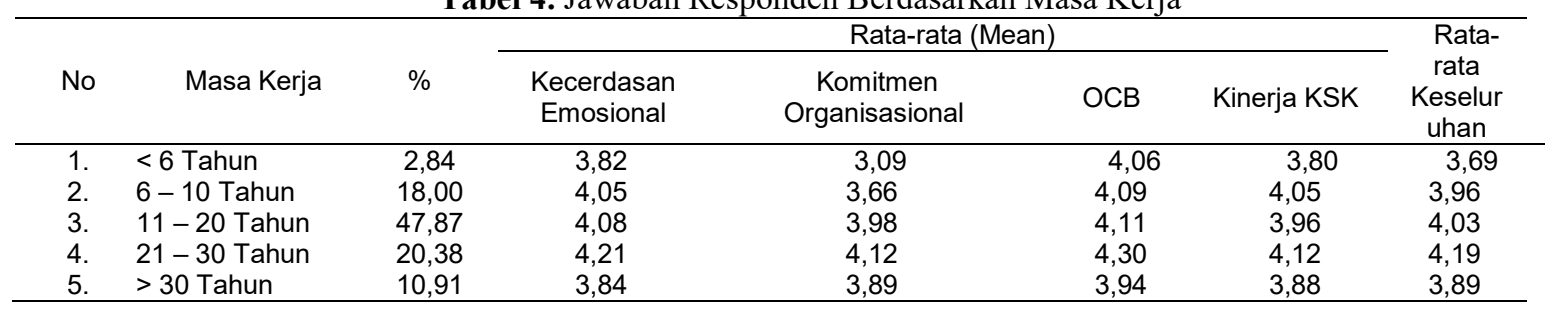

Pada penelitian ini ada 3 (tiga) variabel bebas yang diuji yaitu kecerdasan emosional, komitmen organisasional, OCB dan 1 (satu) variabel terikat yaitu kinerja Koordinator Statistik Kecamatan.

Tabel 5. Skor Rata-rata per Variabel

\begin{tabular}{|c|c|c|c|}
\hline No. & $\begin{array}{l}\text { Variabe } \\
1\end{array}$ & $\begin{array}{c}\text { Rata-rata } \\
(\text { Mean })\end{array}$ & Kategori \\
\hline & Kecerdasan & & Sangat baik \\
\hline 1. & $\begin{array}{l}\text { Emosional } \\
(\mathrm{X} 1)\end{array}$ & 4,07 & \\
\hline & Komitmen & & Baik \\
\hline 2. & $\begin{array}{l}\text { Organisasional } \\
\text { (X2) }\end{array}$ & 3,92 & \\
\hline 3. & OCB (X3) & 4,12 & Sangat Baik \\
\hline 4. & $\begin{array}{l}\text { Kinerja KSK } \\
\text { (Y) }\end{array}$ & 4,00 & Sangat Baik \\
\hline
\end{tabular}

Penelitian ini menggunakan metode analisis data dengan menggunakan software SmartPLS yang dijalankan dengan media komputer. PLS (Partial Least Square) merupakan analisis persamaan struktural (SEM) berbasis varian yang secara simultan dapat melakukan pengujian model pengukuran sekaligus pengujian model struktural. Model pengukuran digunakan untuk uji validitas dan reabilitas, sedangkan model struktural digunakan untuk uji kausalitas (pengujian hipotesis dengan model prediksi). Pengukuran model kecocokan PLS SEM terdiri dari Outer Model dan Inner Model.

Uji reliabilitas diperlukan untuk mengukur stabilitas dan konsistensi dari suatu instrumen dalam mengukur suatu konsep atau variabel. Pada penelitian ini, reliabilitas dapat diukur dengan melihat nilai composite reliability. Jogiyanto (2011) menyebutkan bahwa composite reliability mengukur nilai sesungguhnya reliabilitas suatu variabel. Disebutkan juga bahwa untuk dapat dikatakan suatu variabel itu reliable jika memiliki nilai composite reliability $>0.7$. Hasil untuk uji reliabilitas penelitian ini dapat dilihat pada tabel 6 . 


\section{Jurnal Ilmiah Manajemen dan Bisnis}

ISSN 1693-7619 (Print) I ISSN 2580-4170 (Online) | http://jurnal.umsu.ac.id/index.php/mbisnis

Tabel 6. Nilai Composite Reability

\begin{tabular}{lcl}
\hline \multicolumn{1}{c}{ Variabel } & $\begin{array}{c}\text { Composite } \\
\text { Reliability }\end{array}$ & Hasil \\
\hline $\begin{array}{l}\text { Kecerdasan } \\
\text { Emosional }\end{array}$ & 0.8475 & Reliable \\
Komitmen & 0.8900 & Reliable \\
$\begin{array}{l}\text { Organisasional } \\
\text { OCB }\end{array}$ & 0.9059 & Reliable \\
Kinerja & 0.9082 & Reliable \\
Karyawan & & \\
\hline
\end{tabular}

Evaluasi pertama pada inner model dilihat dari nilai $R$-Square. Berdasarkan pengolahan data dengan SmartPLS 2.0, dihasilkan nilai $R$-Square sebesar 0.7589 , memiliki arti bahwa prosentase besarnya keragaman data pada variabel kinerja yang dapat dijelaskan oleh variabel kecerdasan emosional, komitmen organisasional dan Organizational Citizenship Behavior (OCB) adalah sebesar 75,89\%, sedangkan sisanya yaitu 24,11\% dijelaskan oleh variabel lain selain kecerdasan emosional, komitmen organisasional dan Organizational Citizenship Behavior (OCB). Dengan kata lain dapat diinterpretasikan bahwa kecerdasan emosional, komitmen organisasional dan
Organizational Citizenship Behavior (OCB) berpengaruh sebesar 75,89 \% terhadap kinerja Koordinator Statistik Kecamatan.

Pengujian selanjutnya dapat dilakukan dengan melihat nilai koefisien path atau inner model yang menunjukkan tingkat signifikansi dalam pengujian hipotesis. Dalam hal melihat signifikansi hubungan antar variabel maka yang digunakan adalah analisis T-test dari koefisien jalur (path coefficient). Hipotesis penelitian dapat diterima jika nilai T-statistics lebih dari 1,96. Berikut nilai koefisien estimasi dan nilai $T$-statistics yang dihasilkan pada penelitian ini :

Tabel 8. Nilai Koefisien Estimasi dan T-Statistics

\begin{tabular}{|c|c|c|}
\hline Hipotesis & Koefisien & T Statistics \\
\hline $\begin{array}{l}\text { Kecerdasan } \\
\text { Emosional -> } \\
\text { Kinerja }\end{array}$ & 0,178 & 2.6618 \\
\hline $\begin{array}{l}\text { Komitmen } \\
\text { Organisasional -> } \\
\text { Kinerja }\end{array}$ & 0,014 & 0.1381 \\
\hline OCB -> Kinerja & 0,730 & 8.6729 \\
\hline
\end{tabular}

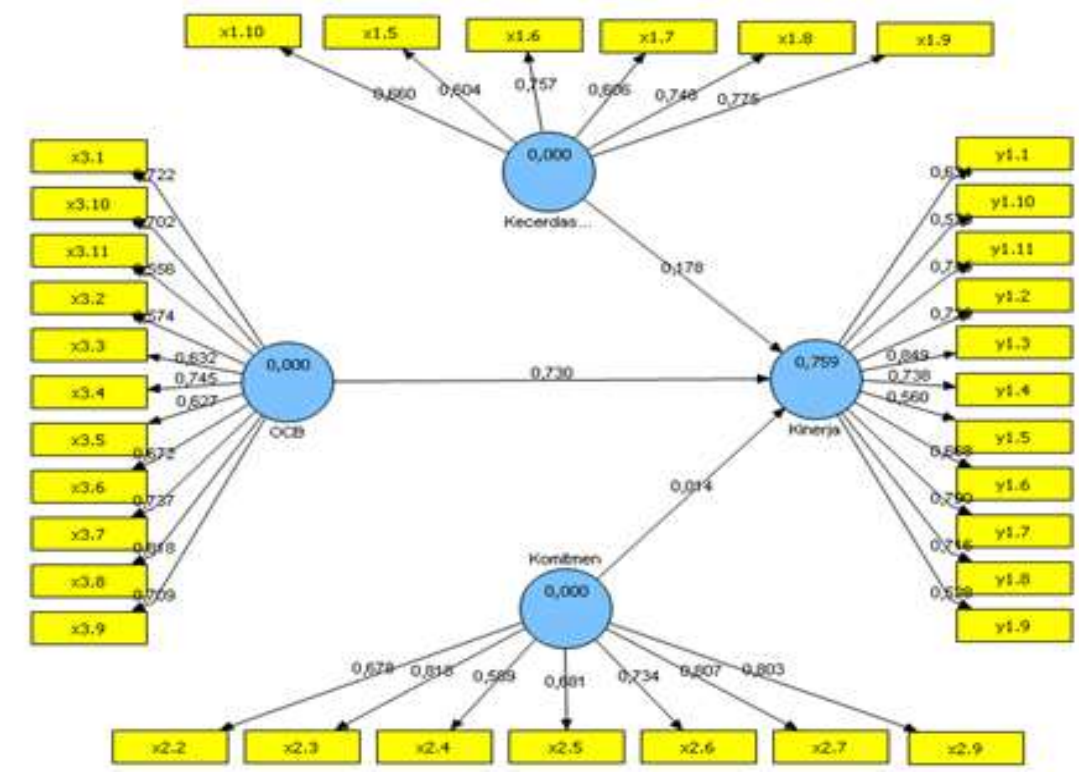

Gambar 1. Koefisien Hasil PLS 


\section{Jurnal Ilmiah Manajemen dan Bisnis}

Setelah melakukan pengujian validitas dan reliabilitas pada keseluruhan dalam model penelitian ini, langkah selanjutnya adalah melakukan analisa apakah variabel-variabel independent yang membentuk model penelitian ini memiliki pengaruh yang signifikan terhadap variabel dependent. Metode yang digunakan untuk analisa ini adalah metode Structural Equation Model (SEM), peneliti menggunakan program SmartPLS 2.0.

Uji hipotesis dilakukan dengan melihat $T$-statistics dan path-coefficient. Nilai $T$ statistics menunjukkan signifikan variabel, sedangkan path-coefficient menunjukkan sifat hubungan antar variabel (positif atau negatif).

Tabel 9. Hasil Uji Hipotesis

\begin{tabular}{lccc}
\hline \multicolumn{1}{c}{ Hipotesis } & Koefisien & $\begin{array}{c}T \\
\text { Statistics }\end{array}$ & Hasil \\
\hline $\begin{array}{l}\text { Kecerdasan } \\
\text { Emosional -> }\end{array}$ & 0,178 & 2.6618 & Diterima \\
$\begin{array}{l}\text { Kinerja } \\
\text { Komitmen }\end{array}$ & 0,014 & 0.1381 & Ditolak \\
$\begin{array}{l}\text { Organisasional } \\
->\text { Kinerja }\end{array}$ & 0,730 & 8.6729 & Diterima \\
$\begin{array}{l}\text { OCB -> } \\
\text { Kinerja }\end{array}$ & 0,0 \\
\hline
\end{tabular}

\section{Pembahasan}

Hipotesis terdukung apabila nilai tstatistik lebih besar daripada nilai t-tabel sebsar 1.96. Koefisien beta mempunyai nilai positif untuk menjelaskan hubungan antara kedua variabel yang diteliti. Koefisien beta berada dalam rentang -1.0 sampai 1.0.

Hipotesis pertama $\left(\mathrm{H}_{1}\right)$ menyatakan persepsi tentang kecerdasan emosional berpengaruh positif dan signifikan terhadap kinerja Koordinator Statistik Kecamatan. Berdasarkan hasil penelitian nilai koefisien estimasi pengaruh kecerdasan emosional terhadap kinerja Koordinator Statistik Kecamatan adalah sebesar 0,178 dengan $t$ statistics sebesar 2,6618 yang lebih besar dari nilai t-tabel 1,96. Hal ini menunjukkan bahwa terdapat pengaruh positif yang signifikan antara kecerdasan emosional terhadap kinerja Koordinator Statistik Kecamatan. Dari hasil ini maka hipotesis pertama dari penelitian ini dapat diterima kebenarannya. Hasil ini sesuai dengan penelitian (Ariesta, 2017; Fitriastuti, 2013; Ibrahim, 2013) yang menemukan hubungan dan pengaruh positif antara kecerdasan emosional dan kinerja.

Menurut teori Goleman (2015) menyebutkan bahwa terdapat hubungan antara kecerdasan emosional terhadap kinerja. Kesadaran diri yang baik membuat KSK mempunyai keyakinan diri sehingga mampu membuat keputusan yang baik dalam kondisi tidak pasti dan tertekan. Seorang KSK yang mampu mengontrol emosi diri yang baik akan memiliki rasa tanggung jawab dan kemampuan beradaptasi dalam menghadapi responden. Kemampuan untuk memotivasi diri sendiri akan membuat KSK bersemangat dalam bekerja, sehingga kinerjanya akan meningkat. Kemampuan berempati menjadikan seorang KSK lebih mudah untuk diterima responden, begitu pula hal yang sama dirasakan oleh responden meski memiliki perbedaan sudut pandang. Ketrampilan sosial seorang KSK bermanfaat untuk menyelesaikan perselisihan dan bekerja sama dalam tim.

Hipotesis kedua $\left(\mathrm{H}_{2}\right)$ menyatakan persepsi tentang komitmen organisasional berpengaruh positif namun tidak signifikan terhadap kinerja Koordinator Statistik Kecamatan. Hal ini ditunjukkan dengan nilai koefisien estimasi pengaruh komitmen organisasional terhadap kinerja Koordinator Statistik Kecamatan adalah sebesar 0,014 dengan $t$-statistics sebesar 0,1381 yang lebih kecil dari nilai t-tabel 1,96. Dari hasil ini maka hipotesis kedua dari penelitian ini ditolak kebenarannya. Variabel komitmen organisasional tidak memberikan efek/dampak langsung yang berarti terhadap variabel kinerja KSK. Hal ini tidak sesuai 


\section{Jurnal Ilmiah Manajemen dan Bisnis}

ISSN 1693-7619 (Print) I ISSN 2580-4170 (Online)

dengan hasil penelitian Carmeli, (2004) bahwa komitmen adalah ukuran bagi kinerja individu dengan kepuasan kerja menjadi variabel moderator antara komitmen dan kinerja.

Penelitian ini sejalan dengan Chairuddin et al., (2015) yang menyatakan bahwa temuan dari studi komitmen organisasional adalah hubungan yang berpengaruh kecil antara komitmen organisasional dan kinerja karyawan. Gunawan \& Gunawan (2019) mengadakan penelitian mengenai praktek sumber daya manusia, kekuatan sumberdaya manusia, komitmen afektif, dan kinerja karyawan. Penelitian Darman, Hamzah et al., (2017) menyatakan bahwa komitmen tidak signifikan mempengaruhi kinerja.

Beberapa faktor penyebab komitmen tidak berpengaruh signifikan terhadap kinerja yaitu adanya mutasi pegawai. Di lingkungan BPS, mutasi berlaku merata untuk semua pegawai baik di jabatan struktural maupun fungsional, vertikal maupun horizontal. BPS adalah instansi pemerintah pusat, sehingga ruang lingkup mutasi mencakup seluruh wilayah di Indonesia. Pola mutasi sendiri selama ini tidak jelas, apakah berdasarkan kinerja, daerah asal atau lain sebagainya. Ketidakjelasan pola mutasi ini tentu merepotkan KSK misalnya dari sisi hubungan mereka dengan keluarga, biaya hidup yang meningkat terutama bagi KSK yang sudah berkeluarga namun tinggal terpisah dengan keluarganya karena terkena mutasi, dan lain sebagainya. Hal ini didukung oleh banyaknya responden yang menginginkan adanya pola mutasi yang jelas. Disarankan agar pola mutasi diperjelas dan disesuaikan dengan daerah asal masing-masing KSK.

Selain itu, penyebab komitmen organisasional tidak berpengaruh signifikan terhadap kinerja KSK juga dikarenakan oleh komitmen menjadi bagian dari BPS yang cukup rendah, terbukti dengan nilai loading factor yang paling rendah. Beban kerja yang cukup tinggi namun tidak mendapat balasan berupa penghargaan yang layak, menjadi alasan utama mengapa komitmen terhadap organisasi tidak begitu baik. Anggapan yang masih melekat bahwa KSK merupakan tingkatan yang paling rendah di BPS yang bertugas hanya sebagai pekerja kasar.

BPS berharap agar KSK lebih meningkatkan komitmennya di instansi sehingga kedepannya KSK dapat setia dalam tugas dan tanggung jawabnya sebagai anggota organisasi. Sehubungan hasil penelitian yang dilakukan menunjukan variabel komitmen organisasi belum memberikan pengaruh terhadap kinerja KSK.

Aspek komitmen organisasional, perlu ditingkatkan kemampuan KSK dengan diklat berkala tentang layanan statistik dan interpersonal skill serta pemberian kesempatan melanjutkan jenjang pendidikan lebih tinggi. Selain itu, pemberian sistem insentif dengan model grade tetap perlu dilanjutkan dan ditinjau secara berkala untuk mempertahankan komitmen berkelanjutan dari KSK. Perlu juga dilakukan program yang membuat KSK merasa bangga menjadi keluarga besar BPS, misalnya dengan menyelenggarakan acara family gathering, pemberian penghargaan kepada KSK teladan, dan sejenisnya yang akan meningkatkan komitmen.

Hipotesis ketiga $\left(\mathrm{H}_{3}\right)$ menyatakan persepsi tentang OCB berpengaruh positif dan signifikan terhadap kinerja Koordinator Statistik Kecamatan. Berdasarkan hasil penelitian nilai koefisien estimasi pengaruh Organizational Citizenship Behavior (OCB) terhadap kinerja Koordinator Statistik Kecamatan adalah sebesar 0,730 dengan $t$ statistics sebesar 8,6729 yang lebih besar dari nilai t-tabel 1,96. Hal ini menunjukkan bahwa terdapat pengaruh positif yang signifikan antara Organizational Citizenship Behavior 


\section{Jurnal Ilmiah Manajemen dan Bisnis}

ISSN 1693-7619 (Print) I ISSN 2580-4170 (Online)

(OCB) terhadap kinerja Koordinator Statistik Kecamatan. Hasil ini mendukung hipotesis ketiga dari penelitian ini. Hasil ini sesuai dengan penelitian (Ariesta, 2017; Fitriastuti, 2013; Ibrahim, 2013) yang menemukan hubungan dan pengaruh positif antara OCB dan kinerja.

Menurut Robbins (2008: 40) Organizational Citizenship Behavior adalah perilaku individu atau perseorangan yang sukarela dan bukan bagian dari syarat formal pekerjaan, tetapi dapat meningkatkan fungsi efektif organisasi. KSK merupakan aset dari BPS. Kontribusi KSK dapat meningkatkan produktivitas BPS. OCB dari KSK dapat meningkatkan kinerja BPS karena perilaku ini merupakan "pelumas" dari mesin sosial dalam organisasi. Dengan kata lain, dengan adanya interaksi sosial pada KSK organisasi menjadi lancar, mengurangi terjadinya perselisihan, dan meningkatkan efisiensi. Dengan OCB KSK dapat meningkatkan produktivitas dari KSK tersebut.

\section{SIMPULAN}

Hasil uji $R$-Square menunjukkan nilai 0,7589 atau $75,89 \%$ yang memiliki arti bahwa variabel kinerja Koordinator Statistik Kecamatan dipengaruhi oleh variabel kecerdasan emosional, komitmen organisasional dan Organizational Citizenship Behavior (OCB) adalah sebesar 75,89 \%, sedangkan sisanya yaitu $24,11 \%$ dipengaruhi oleh variabel lain selain kecerdasan emosional, komitmen organisasional dan Organizational Citizenship Behavior (OCB). Berdasarkan simpulan, maka saran yang bisa disampaikan adalah KSK diberikan pelatihan khusus untuk mengasah dan meningkatkan kemampuan dalam mengelola kecerdasan emosional yang dimilikinya, terutama ketika menghadapi responden dan mengelola beban pekerjaannya. Sebab saat ini pekerjaan KSK semakin banyak dengan jadwal yang bertumpuk. Kepala BPS kabupaten/Kota sebagai atasan wajib membangun hubungan yang harmonis dan berkualitas dengan KSKnya serta mampu meyakinkan mereka agar KSK merasa dihargai keberadaannya dan terpenuhi semua hak-haknya. Kepala BPS Kabupaten/Kota juga harus mampu bertindak adil pada seluruh KSK serta mengajak untuk mencapai tujuan organisasi. Selain itu, KSK diberi kesempatan yang sama dengan pegawai lainnya untuk memberikan masukan dan saran atas kebijakan kantor sehingga pada diri KSK timbul rasa saling memiliki dan dihargai sebagai salah satu unsur di BPS Kabupaten/Kota.

\section{REFERENSI}

Ariesta, I. (2017). Pengaruh Kecerdasan Emosional Dan Organizational Citizenship Behavior (OCB) Terhadap Kinerja Peternak Ayam Ras Pedaging. JBMP (Jurnal Bisnis, Manajemen Dan Perbankan), 2(2), 121. https://doi.org/10.21070/jbmp.v2i2.1098

Carmeli, A. (2004). Article information: International Journal of Organization Theory and Behavior, 6(4), 289-309.

Chairuddin, S., Riadi, S. S., Hariyadi, S., \& . S. (2015). Antecedent Work Engagement and Organizational Commitment to Increase the Outsourcing Employees Performance in Department of Cleanliness and Horticultural. European Journal of Business and Management, 7(14), 1-14. http://www.iiste.org/Journals/index.php/ EJBM/article/view/22476

Darman, Hamzah, D., Taba, M. I., \& Mardiana, R. (2017). The Effect of Personality , Ability , Organizational Support , Job Satisfaction and Organizational Commitment towards Lecturer Performance of Private University in Gorontalo. Scientific 


\section{Jurnal Ilmiah Manajemen dan Bisnis}

ISSN 1693-7619 (Print) I ISSN 2580-4170 (Online) | http://jurnal.umsu.ac.id/index.php/mbisnis

Research Journal (SCIRJ), V(VI), 61-70.

Fitriastuti, T. (2013). Pengaruh Kecerdasan

Emosional, Komitmen Organisasional dan Organizational Citizenship Behavior Terhadap Kinerja Karyawan. Jurnal Dinamika Manajemen, V0l. 4 NO., 103114.

Goleman, D. (2015). Emotional Intelligence: Kecerdasan Emosional, Mengapa EI lebih penting daripada IQ. PT Gramedia Pustaka Utama.

Gunawan, M. A., \& Gunawan, H. (2019). Compensation, Competence, Organizational Commitment and Its Effect on Employee Performance: Job Satisfaction as Interverning. 4(2), 144149.

Ibrahim, I. (2013). Pengaruh Kecerdasan Emosional Terhadap Rganizational Citizenship Behaviord Dan Dampaknya Pada Kinerja Perawat Rumah Sakit Umum Anutapura \& Rumah Sakit Undata Palu. Katalogis, 1(1), 136-146.

Jogiyanto, H. . (2011). Konsep dan Aplikasi Structural Equation Modeling Berbasis Varian dalam Penelitian Bisnis. UPP STIM YKPN.

Luthans, F. (2006). Perilaku Organisasi. Andi.

Organ, D. W. (2006). Organizational Citizenship Behavior. Its Nature, Antecendents, and Consequences. Sage Publication.

Robbins, S. P. (2008). Perilaku Organisasi (2nd ed.). Salemba Empat. 